\title{
THE KEY ROLE OF UNDERLYING THEORIES FOR SCIENTIFIC EXPLANATIONS: \\ A DARWINIAN CASE STUDY
}

\author{
DANIEL BLANCO \\ CEFHIC, UNQ - UNL, ARGENTINA \\ danielblanco.fb@gmail.com \\ ARIEL ROFFÉ \\ CEFHIC, UNQ - CONICET - UBA, ARGENTINA \\ ariroffe@hotmail.com \\ SANTIAGO GINNOBILI \\ CEFHIC, UNQ - CONICET - UBA, ARGENTINA \\ santi75@gmail.com
}

\begin{abstract}
A given explanatory theory $T$ falls into circular reasoning if the only way to determine its explanandum is through the application of $T$. To find an (often previous) underlying theory $T^{\prime}$ that determines $T^{\prime}$ s explanandum helps us save $T$ from this accusation of circularity. We follow the structuralist view of theories in presenting and dealing with this issue, by applying it to particular theories. More specifically, we focus on the relationship between the Darwinian theory of common ancestry and the determination of homologies.
\end{abstract}

Keywords: circular explanation $\bullet$ homology $\bullet$ structuralism $\bullet T$-theoretical terms $\bullet$ theory of common ancestry

\section{Introduction}

Scientific explanation is a broad and multifaceted topic within the realm of the philosophy of science, and it spans an overwhelmingly large literature. Our specific goal in this contribution focuses on one key aspect from that set of matters: the relevance of underlying theories for obtaining healthy, non-circular scientific explanations. Succinctly, what is at stake is how concepts are determined, or, more specifically, how the users of particular theories get their respective explananda. The answer to that question impacts the quality of the resulting explanations in the sense that we are dealing with.

We will address this topic by appealing to the $T$-theoreticity distinction from metatheoretical structuralism (Sneed 1971; Kamlah 1976; Balzer \& Moulines 1980; Balzer; Moulines \& Sneed 1987). We will argue, both generally and specifically (with 
a theory that has been accused of being circular), that scientific theories might avoid explanatory circularity by characterizing their respective explananda with concepts that are non-theoretical for those theories (i.e. with concepts that can be determined independently from them). As we will see, to explicate this aspect of explanation is not only important for general meta-theoretical purposes but also because, once applied to particular theories, it sheds light into current debates within several disciplines.

In the remainder of the text we proceed as follows. Firstly, in section 2, we generically introduce the problem of explanatory circularity and some rudiments of the meta-theoretical approach we use, both to explicate that problem and to offer a possible satisfactory solution: the structuralist view of theories. We then illustrate how this solution works with two preliminary case examples: the theory of classical particle mechanics (CPM hereafter), and the theory of natural selection (TNS hereafter).

Secondly, in section 3, we introduce our central case study: the theory of common ancestry (TCA hereafter). We discuss an issue that currently divides cladists, into those who think that homologies can and should be determined without taking into account evolutionary hypotheses (pattern cladists) and those who think that homologies should definitely be determined using evolutionary theory (phylogenetic cladists). As we will see, our issue relates to important controversies in the context of the philosophy of biology (ones that even predate the cladistic research program, which originated with Hennig's, 1950, seminal work). As a byproduct of these considerations, we hope to show the relevance of historical approaches to this discussion about inter-theoretical links in the field of the philosophy of science.

Finally, we offer our conclusions.

\section{A path to avoid circularity in scientific explanations}

\subsection{How testing works}

As is well known, the testing of theories is indirect, in the sense that it takes place via a comparison between the predictions inferred from those theories and something else, namely, the results of our empirical examinations. It is very important that the way we determine those former predictions be different than the way we determine those latter results, because if the theory under test was responsible both for the prediction and the results, the comparison would be vacuous, and the theory would be always correct/confirmed for viciously circular reasons. Then, an obvious desideratum for an adequate explication of the process of theory testing is that it should not lead us to consider our theories to be right for the wrong reasons, in this case, for committing circularity. 
In other words, if we find that a certain theory $T$ is well confirmed, how can we be sure that its success is not due to spurious reasons? The key is that what counts as the "empirical basis" of $T$ at the time of testing be determined differently than what counts as a prediction inferred from $T$. What makes testing meaningful is that the comparison takes place between (1) what we would theoretically expect, that is, what $T$ predicts, and (2) what we find "in the world" without the intervention of $T$. The requirement is that the theory that makes the prediction should be different than whatever determines what is compared with those predictions. Note that the determination of (2) might well involve applying some theory/ies too. The only requirement is that these theories be different from $T$. This helps us to avoid the unattainable demand from classical approaches, according to which the statements that make up the empirical basis of a theory have to refer only to observational entities (i.e. use only concepts that are free from every theory). Conversely, the out-of-reach theoretical neutrality (Fleck 1986; Hanson 1958) is not a necessary requirement now, as long as what we require is only that "the world" is not theory-laden with the particular theory from which the prediction was inferred.

A similar point to the one made above regarding healthy testing can be made with respect to healthy explanation. ${ }^{1}$ We understand the explanandum of a theory $T$ as the set of systems whose behavior we aim to explain with $T$. This is a global sense of the term, different from the local sense in which Hempel and Oppenheim speak of explanandum (Hempel and Oppenheim 1948), as the objective of particular explanations. What a theory is meant to explain logically (and usually historically) precedes the theory in question. This must be the case, since it should be possible (at least in principle), that there are different, rival and incompatible theories that struggle to explain the same phenomena. If the explanandum of a theory is always semantically dependent on that very theory, this would not be possible. Again, it is necessary to show that what we intend to explain with $T$ can be determined independently of $T$.

This does not deny that there is a dynamic relation between what $T$ is meant to explain and the explanation given by $T$. On the contrary, a close relationship between both things does take place (we will return to this in the next section). Our point is that whatever that relation is, it should not have to do with determination issues.

The structuralist view of theories (Sneed 1971; Balzer; Moulines \& Sneed 1987; Díez 2002; 2012; Falguera, 2012; Lorenzano, 2012a, 2012b; cf. Putnam 1962; BarHillel 1970; Hempel 1970; Lewis 1970) offers an appropriate way to deal with this scenario.

\subsection{The structuralist approach to the problem}

Having rejected (for multiple reasons) the inadequate theoretical-observational classical dichotomy when dealing with theoretical concepts, structuralists distinguish in- 
stead between theoretical and non-theoretical terms within the vocabulary of a given theory. The way they establish this demarcation has nothing to do with observationrelated abilities, and everything to do with how we determine every particular term in that vocabulary.

Shortly, the criterion is as follows: if a concept $x$ belongs to the vocabulary of theory $T$, then $x$ is -in structuralist jargon - " $T$-non theoretical" if and only if we can find the extension or value of $x$ without the intervention of $T$ (we do not need to apply $T$ to get the denotation of $x$ ). Conversely, if the only way we can know the extension or value of $x$ is through the application of $T$, then - again, in structuralist jargon $-x$ is said to be "T-theoretical" (we inescapably need $T$ to determine $x$ ). Note that $T$-theoreticity is a relational term: a concept $x$ might be $T$-theoretical for some theory $T$, and at the same time be $T^{\prime}$-non-theoretical for some other (usually posterior) theory $T^{\prime}$.

Every $T$-theoretical term presupposes $T$, in the sense that it cannot be determined independently of $T$. Regarding $T$-non-theoretical terms, and as we suggested in the previous section, even though they are not "loaded" with $T$ (they can be determined independently of $T$ ), they might well be "loaded" with other theories, so that a theoretical presupposition might be involved in their determination too. Perhaps (we remain agnostic on this) each and every concept in science is theoretical for some particular scientific theory.

For our present goal of showing that the scientific theories we currently use are non-circular, what we require is not that the concepts in the "empirical basis" of a given theory (i.e. the ones we use to test it) are not loaded with any theory (i.e., are observational in the traditional sense), but only that these concepts are free from the specific theory under test (i.e. can be determined independently from it). That is, that with respect to any given theory $T$, the concepts in its "empirical basis" must be $T$-non-theoretical.

Regarding explanation, it is also expected that the explanandum of a theory be formulated exclusively with concepts that are non-theoretical for that theory, since the systems whose behavior the theory is meant to explain should be describable and determinable independently from it. ${ }^{2}$ That is, one should be able to recognize a phenomenon to be explained by a theory before applying that theory. Only in this scenario, $T$ can elude the accusations of explanatory circularity. Again, this does not mean that we are not using any underlying theory in order to determine that explananda. The only requirement is that $T$ not be involved, which does not go against the possibility that a different theory might be.

Within the examinations that the structuralists carry out regarding theoricity, the question of circularity is always at least implicitly present. It is part of the work structuralists do to see whether the explanandum of the theory under analysis is nontheoretical for that particular theory, and sometimes it is useful to point out which 
underlying theory is responsible for the determination of the explanandum of $T$ (that is, for the determination of the $T$-non-theoretical terms used in $T$ ). Since those underlying theories are many times temporally previous to $T$ (in addition to being logically previous), the history of science can also have an important role to play within discussions about theoricity.

Returning to the relationship between explanans and explananda, if, in fact, some theory $T^{\prime}$ has to do with the determination of what $T$ is taken to explain, what we find is an inter-theoretical link between $T$ and $T^{\prime}$ that captures the close dynamical relation in scientific explanation we mentioned before. $T$, far from being a rival of $T^{\prime}$, "uses" it, borrowing the concepts that figure in its explanandum.

Let us consider two preliminary examples before we get to our central case study.

\subsubsection{Case example 1: CPM and the determination of accelerations}

Isaac Newton intended that his CPM explain kinematic trajectories through the postulation of masses and forces that interact with particles, affecting their state of movement in a way detailed in the second principle $(\mathrm{F}=\mathrm{ma})$. In its vocabulary, CPM includes particles, positions, times, masses and forces. However, even though these concepts all belong to the same theory, they are not on the same level once we focus on how they are determined.

In the context of our work, then, what we would demand from this theory is that particles and their accelerations (the concepts that figure in the explanandum of this theory) can be determined independently from it; that is, that they be CPMnon-theoretical terms. And that is exactly the case: we can measure accelerations of particles without utilizing the laws of CPM.

This independence is what allows us to test CPM without the risk of circularity: we can compare the acceleration CPM predicts (a datum determined by the theory) with the acceleration we calculate using non-CPM tools (a datum not determined by the theory, although, one more time, another theory might be involved in this second calculation). The confirmation of a theory involves precisely the coincidence between a theoretical determination of a concept with a non-theoretical determination of the same concept. In case of a coincidence between both determinations (or at least an approximate coincidence), we can be sure that CPM has been confirmed for adequate reasons, that is, that CPM has found a genuine successful application not contaminated with circularity.

Even if we recognize one theory involved in our second calculation, that theory is doubtlessly not CPM. Then, as CPM-non theoretical terms, particles and accelerations belong to the "empirical basis" of CPM (which plays a role similar to the one that observational terms had in classical approaches, although observation does not necessarily play a role here). On the other hand, their theoretical status may not 
be the same in the realm of the theory/ies (different from CPM) we used to determine them (for example, acceleration may be a $T^{\prime}$-theoretical concept in a different theory $T^{\prime}$ ).

Note that it is also possible to determine accelerations with the resources of CPM, thanks to the second principle. What we want to stress is the fact that it is also possible to determine them without CPM resources. The fact that both things are possible is what makes accelerations relevant for testing CPM. When the testing involves a comparison between both kinds of determinations, circularity can be dismissed.

In fact, the history of science shows that the determination of accelerations is independent of CPM, because accelerations were measured before Principia Mathemathica (1687) was published. Again, this confirms the insight that "acceleration" is a CPM-non theoretical term, belonging to the empirical basis of CPM.

\subsubsection{Case example 2: TNS and the determination of adaptations}

Darwin explicitly proposes TNS to account for the presence of adaptations. "Adaptation" is a multivocal notion. It is sometimes used to name those functional traits that emerged by natural selection, that is, traits whose origin are indeed explained by natural selection; while at other times, it is used to name the functional traits whose origin natural selection aims to explain (Burian 1992; Ginnobili 2016, 2019; WestEberhard 1992). The use of the term that interests us here is the second. Given that we intend TNS to explain the origin of adaptations (in this second sense), then adaptations themselves (again, in this second sense) must be determinable independently from it (i.e. must be determinable TNS-non-theoretically).

On the other hand, as Darwin himself points out, there are other theories that try to account for the same phenomena of the presence of adaptations, such as Lamarckian use and disuse plus the inheritance of acquired characters, and the nineteenthcentury versions of intelligent design. (In fact, it is well known that Darwin himself sometimes used Lamarckian explanations while rejecting Paleyan ones on grounds of scientificity.) To some extent, these three theories share their explanandum (cf. Blanco 2008; Caponi 2011, 2020).

When we said "to some extent", we meant to clarify that we do not intend to claim that the set of explananda that Lamarck, Paley or Darwin had in mind were mutually co-extensive. Surely, they were not. Darwin helps us to "see" adaptations that Paley would never conceive possible to exist and vice versa (Caponi 2011; Ginnobili 2014). For instance, in the Darwinian world, a trait that helps others at the expense of the bearer would not exist (Darwin 1859, p.199). But even in the case that a particular theory might guide us to see new applications for itself, the epistemic requirement remains the same: those new explananda should be determined without that guiding explanatory theory. 
It is easy to show that an adaptation, for Paley as well as for Darwin or Lamarck, is a trait that fulfills a function in a highly effective way. As we have stressed, if the presence of adaptations (traits that effectively perform at least one function) is what all these theories are taken to explain, then the presence of adaptations must be determinable independently from each of them (since they also do not presuppose one another, but rather are rivals). That is, the functional attribution must be able to be carried out independently of TNS.

Since non-theoretical determinations of the non-theoretical concepts from a given theory usually appeal to other underlying or presupposed theories, an interesting consequence emerges, one that has not always been taken into account within the literature about functional explanation. We should expect there to be a theory that is independent from TNS, that regulates functional attribution; or, at least, that the attribution of a function is independent of TNS (cf. Cummins, 1975). ${ }^{3}$

As we will see in the next section, a similar situation takes place in the other great theory that Darwin left us: TCA. In the next section we will be considering a point where this theory intersects with systematics, specifically, a discussion that takes place within cladistics. As we will see, it has everything to do with our topic.

\section{Case study: TCA and the determination of homologies}

\subsection{Homology and the explanandum TCA}

Despite their agreements in many key respects, pattern and phylogenetic cladists are divided in several others. Our concern has to do with only one of these topics of conflict: can/should we determine homologies without taking into account phylogenetic hypotheses?

Pattern cladists claim that we do not require any knowledge of evolution to establish homologies. According to them, patterns of character traits are enough for us to determine the cladistic categorization of species, allowing cladists to remain agnostic on the particulars of evolutionary histories (Pearson 2010, p. 476; Brower 2000; 2019).

Note how our meta-theoretical problem rises again: surely cladists aim to explain the presence or the distribution of homologies by appealing to phylogenetic hypotheses; but, can they find homologies independently of Darwin's TCA?

Given all that we have said so far, a positive response to this question is metatheoretically desirable. The reason is that homologies are the explananda of TCA, so we need to find a way to determine homologies without the intrusion of TCA in order to secure an adequate testing of the theory, that is, a testing free from circularity. On the other hand, if the only path leading to the determination of homologies is through TCA, circularity will appear. 
Many authors have previously stressed this risk. For example, Kevin Padian (2007, p.87) suggests that we need independent evidence to determine homologies. The reason is that it would be circular to identify homologous structures with those structures inherited from a common ancestor, and at the same time claim that we know that a set of organisms have a common ancestor because they share homologous structures.

Similarly, Rosenberg and Neander claimed that:

Homologies are "sameness due to common descent" and we must ask what the sameness consists in, for it cannot consist purely in common descent. [... The traits adjudged the same cannot, on pain of circularity, be so judged on hypotheses of homology: their sameness or similarity can be explained by their common descent but it cannot merely consist in their common descent. If all there were to membership in a homologous kind were common descent, it would follow from Darwin's hypothesis of common descent that every organ type is the same as every other, patently a reductio ad absurdum. If we are sensibly to define homology it must be treated as a diagnostic/explanatory kind that presupposes some prior categorization of traits. (Rosenberg and Neander 2008, p.309-310)

While Mayr and Ashlock claimed that:

Relationship between two taxa is most often indicated by the existence of homologous characters, but there is considerable uncertainty about what homology is and how it can be established. [...] When Darwin discovered common descent as the cause of homology, it became possible to adopt a more rigorous definition than the ones suggested by $[\ldots$ his... $]$ forerunners, and yet, 125 years after the publication of the Origin, there is still considerable argument over the definition of homology. The problem is how to avoid a definition that is circular. (Mayr and Ashlock 1991, p.142)

And finally Pearson, thinking now in the context of the cladistics debate introduced above:

For pattern cladists, the source of the mistake in making homology an historical concept lies in its trading in the possibility of a theory-independent empirical basis for taxonomic classification for a theory circular classification. The theory circularity arises because homology is supposed to be evidence for certain evolutionary relationships between taxa. But, if homology conceptually packs in the historical relationship between taxa and their traits, the evidence that homology provides for evolutionary relationships is circular. (Pearson 2010, p.484; cf. Roffé et al. 2018)

Note that all these authors share a common intuition: if homologies are similarities due to (i.e. explainable by) common ancestry, then homologies should be recognizable independently from common ancestry. Again, and now using the terminology 
we introduced in section 2.2, if the presence of homologies constitutes the explanandum of TCA, then those homologies should belong to the set of TCA-non-theoretical terms.

Furthermore, we find here something similar to what happened with "adaptation": as we have said, scientists talk about homologies as the explananda of TCA, but they also talk about homologies once they have explained them —-thanks to TCA - as similarities due to common ancestry. ${ }^{4}$ This forces us to distinguish two kind of homologies (cf. Aboitiz 1988; Wagner 1989; de Pinna 1991; Blanco 2012): $h_{1}$, what are sometimes called "primary homologies", which is what TCA intends to explain (a non-historical conceptualization); and $h_{2}$, which corresponds with those "primary homologies" that have successfully been explained through TCA (a historical conceptualization), sometimes called "secondary homologies". The fact that set $h_{1}$ might have the same extension than set $h_{2}$ is a possibility that should not be assumed a priori. In fact, $h_{1} \subseteq h_{2}$ (more on this in Roffé 2020).

But before we talk about "resemblances due to parenthood" (thanks to TCA), we must learn to recognize these resemblances. Then, the first kind of homologies $\left(h_{1}\right)$ need to be determined without resort to Darwinian common ancestry. Note that we are dealing with some sort of "pre-Darwinian" homologies here, the ones that are the elements of the set of intended applications of TCA. On the other hand, the second kind of homologies $\left(h_{2}\right)$ constitute the set of successful applications of TCA, and cannot be determined without Darwinian TCA, so they can be called "Darwinian" homologies.

Note that the debate within cladism involves our philosophical issue: if the "chunk of the world" we are about to explain $\left(h_{1}\right)$ cannot be determined without the aid of the explanatory theory (TCA), then we have to face a serious conceptual problem. But once we distinguish between these two kinds of homologies, we can see that pattern cladists do have a point (at least in the particular aspect of the determination of homology), which helps us to adopt an approach that is healthy from an explanatory point of view. In conclusion, the kind of homology that cladistics uses should be determined (identified) without insights from TCA, although their presence can later be explained by reference to evolution (common origin, what TCA does).

Let us see now how Darwin himself dealt with the determination of $h_{1}$.

\subsection{On the shoulders of a giant}

It is in the last chapter of Origin where Darwin talks extensively about TCA and its intended applications, by adopting an already-available, non-evolutionary conceptualization of homology. Furthermore, he approved those non-historical conceptualizations to appear in the glossary of the last version of Origin, written by William Dallas (Darwin 1872, p.434-435). In fact, he even used this non-historical concept 
of homology in his large non-evolutionary anatomical studies of barnacles (Darwin 1851) during the first half of the 1850s. It follows, then, that this non-historical conceptualization of homology cannot be due to TCA. In fact, the operational criteria relevant to determine $h_{1}$ are present in a couple of works that predate Origin, and that Darwin definitely read with care.

From the first undertakings in comparative anatomy (thought as an aid for systematics) we can already find the determination of "sameness" $\left(h_{1}\right)$. This can be traced back at least up to the $16^{\text {th }}$ Century. Attempts to formulate more systematic approaches - with German-trascendalist influences such as Lorenz Oken and Johann Goethe - took place first in France with Geoffroy Saint-Hilaire and Étienne Serres, and then in England, with Richard Owen, who is Darwin's main source for this issue (Blanco \& Ginnobili 2020). ${ }^{5}$

Owen, just like Saint-Hilaire and others, defended the importance of comparative anatomy to unite biodiversity through a global classification. ${ }^{6}$ But while his French colleague had as his main objective to unify virtually all forms of life under one and the same single plan, Owen concentrated his efforts in the vertebrates, and -in this area - did a much better work than what had been done before in comparative anatomy. Having laid down the now standard distinction between "homologies" and "analogies" in a useful clarification of the terminological babel within the discipline $(\text { Owen } 1843)^{7}$, Owen started a series of publications on this issue that ranged until the end of the decade of 1840 (Owen 1847; 1849).

And it was thanks to these works that Darwin was able to have a rich set of "recipes" to detect what Owen called "special homologies" $\left(h_{1}\right)$. Owen provided several protocols to recognize these similarities among the vertebrates (Padian 2007), such as embryological and histological clues and the relative positions and connections with other parts of the individual that Saint-Hilaire had talked about two decades before. ${ }^{8}$

Owen's explanatory theory for the presence of homologies postulates the existence of an ideal basic archetype (a new version of Oken's theory of the vertebra). For him, the archetype itself is a multiplication of an ideal vertebra, while the osseous portions in vertebrates are not but embodiments — realizations, actualizations - of modifications of the constituents of the original segments in that ideal vertebra.

His writings include, then, not only a set of procedures to detect homologies, but also an explanatory theory to account for them. What Darwin did (not more, not less) was to adopt an alternative explication for a close-to-be-the-same set of similarities $\left(h_{1}\right)$. He replaced the notion that biodiversity is a result of variations of an abstract model, for the notion that it is a result of variations of an actual organism, a common ancestor (Darwin 1859, p.435-436). And it is this common empirical basis between TCA and the theory of the archetype what makes them rivals.

Explanatory issues aside, the main point for our purposes is that the determina- 
tion of the set $h_{1}$ is the realm from which TCA gets its intended applications. And we can determine $h_{1}$ without/before Origin, using the Owenian topographic criteria that Darwin took into account (see Brady 1985). If we are right on this, then Darwinian TCA is a genuine explanatory theory in the sense that does not fall into circularities insofar as its explanandum is TCA-non theoretical. Then, as far as TCA is concerned, $h_{1}$ is a set of phenomena of the world looking for a scientific explanation.

If we mean to save the modern version of TCA of that very charge, we should find that the determination of its own explanandum is free from that new version of TCA. Again, the concept of homology is still under fire (cf. Boyden 1969; de Beer 1971; Wagner 2014; Lorenzo 2015). Perhaps Owenian criteria are presently not powerful enough (that may be the case in the realm of molecular homologies), but TCAindependent protocols to detect the explanandum of TCA are not only epistemologically desirable, but necessary. ${ }^{9}$

\section{Conclusions}

In sum, we offer the following six conclusions:

(1) If what a given theory $T$ is meant to explain can only be found through the application of $T$, then $T$ faces a charge of circularity. For this reason, it is important to find a way to determine the explanandum of $T$ that is independent of the application of $T$. This is a necessary condition for any genuinely explanatory scientific theory.

(2) The structuralist notion of $T$-theoricity helps us to get an adequate meta-theoretical approach to deal with the problem described in (1). By no means have we suggested this is the only possible approach to solve the problem, but that it is indeed useful to satisfactorily address the mentioned issue.

(3) Clear examples of theories where this desirable independence is met are:

a. CPM, where accelerations of particles (its explanandum) can be determined without/previously to Newton's theory. They are, then, CPM-nontheoretical terms (although they can be "loaded" with other theory/ies).

b. TNS, where functions and adaptations can be determined without/previously to Darwin's Origin. Thusly, they are TNS-non theoretical terms (although they can be "loaded" with other theory/ies).

(4) Darwin had a mature theoretical structure from comparative anatomy available to him - mainly from 1840s works written by Owen-. This structure helped him to recognize a set of "chunks" of nature $\left(h_{1}\right)$ that he would intent to explain using TCA. It follows that (primarily) homologous traits $\left(h_{1}\right)$ 
can be determined without/previously to Darwin's TCA. Therefore, they are TCA-non-theoretical terms in Darwin's version of TCA.

(5) Modern debates that have to do with the determination of the empirical basis of TCA (such as the one we find within cladism) can be decided similarly. Perhaps Owen's criteria are not enough today (see Remane 1952), but whatever the new criteria might be, they should not be loaded with TCA, in order to avoid circularity charges.

(6) More generally, the idea of finding theories that help us to determine terms that later are used by other theories as their explananda reveals the importance that the history of science might have in order to deal with this kind of philosophical problems.

\section{References}

Aboitiz, F. 1988. Homology: A comparative or a Historical Concept? Acta Biotheoretica 37(1): 27-29.

Amundson, R. 2005. The Changing Role of the Embryo in Evolutionary Thought. Cambridge: Cambridge University Press.

Appel, T . 1987. The Cuvier-Geoffroy Debate: French Biology in the Decades before Darwin. New York: Oxford University Press.

Balzer, W. \& Moulines, C. 1980. On Theoreticity. Synthese 44(3): 467-494.

Balzer, W.; Moulines, C. \& Sneed, J. 1987. An Architectonic for Science: The Structuralist Program. Dordrecht: Reidel.

Bar-Hillel, Y. 1970. Neorealism vs. Neopositivism. In: Y. Bar-Hillel (ed.) Aspects of Language. Jerusalem: Magnes Press, p.263-272.

Blanco, D. 2008. La naturaleza de las adaptaciones en la teología natural británica: análisis historiográfico y consecuencias metateóricas. Ludus vitalis 16(30): 3-26.

Blanco, D. 2012. Primera aproximación estructuralista a la Teoría del Origen en Común. Agora 31(2): 171-194.

Blanco, D. \& Ginnobili, S. 2020. Piezas owenianas en el rompecabezas darwiniano. Asclepio 72(2): 315 .

Boyden, A. 1969. Homology and Analogy. Science 164(3878): 455-456.

Brady, R. 1985. On the Independence of Systematics. Cladistics 1(2): 113-126.

Brower, A. 2000. Evolution Is Not a Necessary Assumption of Cladistics. Cladistics 16(1):143156.

Brower, A. 2019. Background Knowledge: The Assumptions of Pattern Cladistics. Cladistics 35(6):717-731.

Burian, R. 1992. Adaptation: Historical Perspectives. In: E. Keller and E. Lloyd (eds.) Keywords in Evolutionary Biology. Cambridge: Harvard University Press, p.7-12.

Caponi, G. 2011. La segunda agenda darwiniana. México: CEFPSVLT.

Caponi, G. 2013. Teleología Naturalizada: Los conceptos de función, aptitud y adaptación en la Teoría de la Selección Natural. Theoria 28(1): 97-114. 
Caponi G. 2020. The Darwinian Naturalization of Teleology. In: L. Baravalle and L. Zaterka (eds) Life and Evolution. History, Philosophy and Theory of the Life Sciences 26. Springer, Cham. https://doi.org/10.1007/978-3-030-39589-6_8

Cummins, R. 1975. Functional Analysis. Journal of Philosophy. 72(20): 741-764.

Darwin, C. 1851. A Monograph of the Sub-class Cirripedia, Vol. 1. London: The Ray Society.

Darwin, C. 1859. On the Origin of Species. London: John Murray, $6^{\text {th }}$ ed. 1872.

de Beer, G. 1971. Homology, an Unsolved Problem. Oxford: Oxford University Press.

de Pinna, M. 1991. Concepts and Tests of Homology in the Cladistic Paradigm. Cladistics 7(4): 367-394.

Diez, J. 2002. A Program for the Individuation of Scientific Concepts. Synthese 130(1): 1348.

Díez, J. 2012. Inconmensurabilidad, comparabilidad empírica y escenas observacionales. In: P. Lorenzano and O. Nudler (eds.) El camino desde Kuhn. La inconmensurabilidad hoy. Madrid: Biblioteca Nueva, p.67-118.

Falguera, J. 2012. Comparación epistémica de teorías inconmensurables, sin fundamentismo. In: P. Lorenzano and O. Nudler (eds.), El camino desde Kuhn. La inconmensurabilidad hoy. Madrid: Biblioteca Nueva, p.119-170.

Fleck, L. 1986. La génesis y el desarrollo de un hecho científico. Madrid: Alianza.

Ginnobili, S. 2009. Adaptación y función - El papel de los conceptos funcionales en la teoría de la selección natural darwiniana. Ludus Vitalis 17(31): 3-54.

Ginnobili, S. 2014. La inconmensurabilidad empírica entre la teoría de la selección natural darwiniana y el diseño inteligente de la teología natural. Theoria 29(3): 375-394.

Ginnobili, S. 2016. Missing concepts in natural selection theory reconstructions. History and Philosophy of Life Sciences 38(8): 1-33.

Ginnobili, S. 2018. La teoría de la selección natural: una exploración metacientífica. Bernal: Universidad Nacional de Quilmes.

Griffiths, P. 2007. The Phenomena of Homology. Biology \& Philosophy 22(5): 643-658.

Hanson, N. 1958. Patterns of Discovery. Cambridge: Cambridge University Press.

Hempel, C. 1970. On the 'Standard Conception' of Scientific Theories. In: S. Radner (ed.) Minnesota Studies in the Philosophy of Science, vol. IV. Minneapolis: University of Minnesota Press, p.142-163.

Hempel, C. \& Oppenheim, P. 1948. Studies in the Logic of Explanation. Philosophy of Science 15(2): 135-175.

Hennig, W. 1950. Grundzüge einer Theorie der phylogenetischen Systematik. Berlin: Deutscher Zentralverlag.

Kamlah, A. 1976. An Improved Definition of "Theoretical in a Given Theory. Erkenntnis 10(3): 349-359.

Lankester, E. 1870. On the use of the term homology in modern zoology. Annals and Magazine of Natural History 6(31): 34-43.

Lewis, D. 1970. How to Define Theoretical Terms. The Journal of Philosophy 66(13): 427-446.

Lorenzano, P. 2012a. Base empírica global de contrastación, base empírica local de contrastación y aserción empírica de una teoría. Ágora 31(2): 71-107.

Lorenzano, P. 2012b. Estructuras y aplicaciones intencionales: Inconmensurabilidad teórica y comparabilidad empírica en la historia de la genética clásica. In: P. Lorenzano and O. 
Nudler (eds.)El camino desde Kuhn. La inconmensurabilidad hoy. Madrid: Biblioteca nueva, p.289-350.

Lorenzo, G. 2015. Homology, an (Un)Solved Problem. Teorema 34(2): 211-223.

Mayr, E. \& Ashlock, P. 1991. Principles of Systematic Zoology. New York: McGraw-Hill.

Mivart, G. 1870. On the Use of the Term 'Homology'. Annals and Magazine of Natural History 32(4): 113-121.

Owen, R. 1843. Lectures on the Comparative Anatomy and Physiology of the Invertebrate Animals. London: Longman Brown Green and Longmans.

Owen, R. 1847. On the Archetype and Homologies of the Vertebrate Skeleton. London: John Taylor.

Owen, R. 1849. On the Nature of Limbs. London: John Van Voorst.

Padian, K. 2007. Richard Owen's Quadrophenia. The Pull of Opposing Forces in Victorian Cosmogony. In: R. Amundson (ed.) On the Nature of Limbs. A discourse by Richard Owen. Chicago: The University of Chicago Press, p.53-91.

Pearson, C. 2010. Pattern Cladism, Homology, and Theory-Neutrality. History and Philosophy of the Life Sciences 32(4): 475-492.

Putnam, H. 1962. What Theories are Not. In: E. Nagel, P. Suppes \& Tarski, A. (eds.) Logic, Methodology and Philosophy of Science. Stanford: Stanford University Press, p.240-251.

Remane A. 1952. Die Grundlagen des natürlichen Systems der vergleichenden Anatomie und der Phylogenetik. Leipzig: Portig.

Roffé, A. 2020. Dynamic Homology and Circularity in Cladistic Analysis. Biology \& Philosophy 35: 21. https://doi.org/10.1007/s10539-020-9737-4

Roffé, A, S. Ginnobili \& Blanco, D. 2018. Theoricity, Observation and Homology: A Response to Pearson. History and Philosophy of the Life Sciences 40(3): 1-8.

Rosenberg, A. \& Neander, K. 2009. Are homologies (selected effect or causal role) function free? Philosophy of Science 76(3): 307-334.

Rupke, N. 2009. Richard Owen: Biology without Darwin. Chicago: University of Chicago Press. Saint-Hilaire, G. 1830. Principes de Philosophie Zoologiqués. Paris: Rousseau Libraire.

Sneed, J. 1971. The Logical Structure of Mathematical Physics. Dordrecht-Holland: Reidel.

Wagner, G. 1989. The Biological Homology Concept. Annual review of Ecology and Systematics 20(1): 51-69.

Wagner, G. 2014. Homology, Genes, and Evolutionary Innovation. Princeton: Princeton University Press.

West-Eberhard, M. 1992. Adaptation: Current Usages. In: E. Keller \& E. Lloyd (eds.), Keywords in evolutionary biology. Cambridge: Harvard University Press, p.13-18.

\section{Notes}

${ }^{1}$ We will sometimes interchange the use of "what $T$ predicts" with "what $T$ explains". We omit here the well-known and oft-quoted objections to this symmetry between prediction and explanation (namely, that we can have prediction without explanation and explanation without prediction). What we assume is that a theory that explains some phenomena, can later predict other phenomena of the same kind. As our concern has to do specifically with explanations, we mostly use the terminology related to this last topic. 
${ }^{2}$ There is an interesting matter to single out here: while it is to be expected that the explanandum of a theory $T$ is formed by $T$-non-theoretical concepts, it does not seem to be the case that every theory has as its explanandum all its $T$-non-theoretical concepts. That is, some theories seem to contain $T$-non-theoretical concepts in their global explanans. In other words, to account for their explanandum, they use some $T$-non-theoretical concepts. This implies that the basis of contrast (the "empirical basis") of a theory does not necessarily coincide with its explanandum. As interesting as this may be, it is not an important point regarding the goals of this paper.

${ }^{3}$ Additionally, it helps us to see a potential problem with the etiological position, because if we claim that functional language is defined using terms from TNS, then we are to face the circularity charge (Caponi 2013; Ginnobili 2009, 2018). That is, if one holds at the same time that: (a) The presence of adaptations constitutes the explanandum of TNS; (b) An adaptation is a trait that performs a function effectively; and (c) The claim "trait $t$ has a function $f$ " is definitionally equivalent to the claim "trait $t$ is present because it was naturally selected for doing $f$ ", we fall into the circularity pointed out before. This is so because TNS would then explain the presence of traits that came about thanks to natural selection, which would render TNS vacuous.

${ }^{4}$ Perhaps the first use of "homology" in terms of common ancestry was pointed out by Ray Lankester. When trying to avoid terminological problems, Lankester (1870) introduced a new term for it: "homogeny". His terminological proposal was unsuccessful, but his new definition was widely accepted, unintentionally generating part of the ambiguous-then-confusing use of "homology" we are describing. The first objection to Lankester was written that very year, as a response to his article and even it has more to do with terminological issues than with conceptual ones, note how it reflects part of our own position. It was written by George Jackson Mivart. He wrote:

I cordially agree as to the desirability of the retention of the term "analogy" in the sense mentioned; but I contend that it is desirable to retain the word "homology" also, and that in the very sense Professor Owen gave to it -namely, a close resemblance of parts as regards their relation to surrounding parts, to whatever cause that resemblance may be due, whether genetic or otherwise. (Mivart 1870, p.115)

Note that Mivart is trying to separate the question of what is to be explained from the question of its explanations, preserving "homology" to name the former, and questioning its use for the latter. The part Owen played in this issue is shortly addressed in the following section.

${ }^{5}$ Owen's position on comparative anatomy was far from being homogenous throughout his prolific career. The influences from the Cuvier-like functionalism were gradually eclipsed by a more structuralist approach (Amundson 2005; Rupke 2009). A nice example is his discussion on the fragmentation in the cranium of human babies, a trait useful for the safety of human mothers at birth. Both the coincidence in the spots of ossification within the group and the presence of similar fragmentations in subgroups where birth is not dangerous for mothers (birds) reveal that the structural explanations are better than the functional ones (Owen 1849, p.9). Ten years later, Darwin (1859, p.197) mentioned the exact same example regarding sutures (Blanco \& Ginnobili 2020).

${ }^{6}$ Even though they parted from very different starting points than that of Darwin, both Saint-Hilaire and Owen believed, as Darwin did, that systematics should not be an artificial sorting of biodiversity. The three of them were looking for a true (or natural) classification. 
"Classification is evidently not arbitrary like the grouping of the stars in constellations." (Darwin 1859, p.411).

${ }^{7}$ Note that what Saint-Hilaire calls "philosophical analogies" are what Owen (and Darwin) calls "homologies", so that these similarities are termed differently by different $19^{\text {th }}$ century authors. Conversely, for Owen (and Darwin) the term "analogy" names similar traits that do not have systematic value, just the opposite from what Saint-Hilaire meant. Another chapter in this confusion is that the words we use to designate traits have often - not always (cf. Griffiths 2007) - to do with what they do: we sometimes use identical terms to name different traits that share the same function, and, conversely, we use different terms to name "the same trait in different variants" with different functions. This was one of the points Saint-Hilaire stressed in his debate against Cuvier in 1830 (Saint-Hilaire 1830; Appel 1987), and the same complaint Owen wrote about at the beginning of his 1847 work.

${ }^{8}$ Owen also talks about "serial homologies", responsible, for example, for the bilateral symmetry within the same individual; and about the hypothesis of "general homology", the general plan for Vertebrate taxa, the organizational scheme where he places the archetype (cf. Owen 1847; 1849). It is in this last area where we find the main Platonist mark in his thought. Its detailed treatment is beyond our goals.

${ }^{9}$ Both Griffiths (2007) and Pearson (2010) follow a similar intuition, as both consider that the concept of primary homology is "free of theory". Again, our approach only requires that they be free of TCA, but not necessarily free of any theory at all.

\section{Acknowledgments}

This work has been funded by the following research projects: PUNQ 1401/15 (Universidad Nacional de Quilmes, Argentina), UNTREF 32/15 255 (Universidad Nacional Tres de Febrero, Argentina), PICT-2014-1741 (ANPCyT, Argentina), PICT 2018-3454 (ANPCyT, Argentina), and UBACyT 20020190201537BA (Universidad de Buenos Aires, Argentina). 